Original Research Paper

\title{
Welded Connections of Wind Turbine Towers under Fatigue Loading: Finite Element Analysis and Comparative Study
}

\author{
${ }^{1}$ Nafsika Stavridou, ${ }^{1}$ Evangelos Efthymiou and ${ }^{1,2}$ Charalampos C. Baniotopoulos \\ ${ }^{I}$ Department Civil Engineering, Institute of Metal Structures, Aristotle University of Thessaloniki, Thessaloniki, Greece \\ ${ }^{2}$ School of Civil Engineering, University of Birmingham, Birmingham B15 2TT, United Kingdom
}

\author{
Article history \\ Received: 15-07-2015 \\ Revised: 28-07-2015 \\ Accepted: 28-07-2015 \\ Corresponding Author: \\ Nafsika Stavridou \\ Department Civil Engineering, \\ Institute of Metal Structures, \\ Aristotle University of \\ Thessaloniki, Thessaloniki, Greece \\ Email: nstavrid@civil.auth.gr
}

\begin{abstract}
Increased contemporary energy needs have led to multiple investments on wind power plants and structural improvements are considered necessary for the construction of taller, more robust and more economical structures. Tubular steel wind turbine towers that are the prevailing structural configuration, demand welding of circular subparts to construct the tower structure. These circumferential welds between tower subparts and between the tower and the connecting flanges are proved to be prone to fatigue failure, since cracks are observed in these areas of already constructed wind towers. The aim of the present work is to enlighten weld design procedures of wind turbine tower welds using damage accumulation methods. For the purposes of the comparative study, two towers of same height differing in shell thickness distribution are taken into account. The towers are compared numerically and analytically following two methods of calculating fatigue loads for structures; the first is an analytical method proposed in design codes and the second is by using artificial loading histories produced by the National Renewable Energy Laboratory software. In both methods, shell thickness is proved to be a decisive factor for the fatigue life of the structure and it is often a challenge to design an economic structure with sufficient fatigue life. From the comparison of the tower's welds fatigue life, useful outcomes have been found on the precision of the methods compared and the relation of fatigue life and material used for construction.
\end{abstract}

Keywords: Wind Turbine Tower, Numerical Analysis, Welded Connections Fatigue Life, Artificial Loading History

\section{Introduction}

The challenge of constantly constructing taller wind turbine towers imposes the analytical and detailed structural design of such structures. The investigation of horizontal axis tubular steel wind turbine towers structural behavior has been the aim of on the finite element simulation of the structures the work performed by Bazeos et al. (2002). Refined finite element and simplified models have been analyzed and compared, highlighting the necessity of detailed finite element analyses for the accurate prediction of buckling loads and the calculation of stresses in special locations. Lavassas et al. (2003) after performing the analysis and design of a prototype wind turbine tower concluded also that detailed finite element analysis is appropriate for the determination of the ultimate capacity of the structure. In their work it is mentioned that the dynamic characteristics of the structure, play a vital role for its fatigue design. The governing loads when analyzing the structure against survival aerodynamic conditions are the bending moment and lateral loading deriving from the rotor's function. Dimopoulos and Gantes (2012) focused on the assessment of the bending capacity of wind turbine towers comparing experimental and numerical results and achieving very good agreement between the two. In their study it is proved that in unstiffened shell structures initial imperfections affect their post-buckling behavior. Valuable conclusions on their structural response have been derived from the post-collapse analysis of structures like the work of Lee and Bang (2013), which focused on the simulation of structural failure that led to a collapse of a wind turbine tower in Korea. Comments on the finite element simulation of the structures are made and lessons learnt from existing structures are introduced in contemporary structural guidelines.

Structural analysis guidelines have been incorporated in design codes and there are constantly taller towers 
constructed aiming to cover the increasing energy needs. Despite recent advances integrated in structural codes, wind turbine accidents, failures or even total collapses continue to happen, due to either extreme weather conditions or structural failures, often resulting in great economical losses. In accident reports published by Ragheb (2013) and Raftery (2012) there are variable types of failures that potentially lead to total catastrophes, like blade failures, rotor failures and structural failures. The general term of structural failure implies local buckling failures due to incorrect shell design, fatigue cracks on welds, foundation cracking due to fatigue, corrosion of foundation bolts, residual stresses of internal welds etc. One of the most important reasons of structural failure observed in wind turbine towers is fatigue failure of welds (Khatri, 2009), which has also recently led to the total collapse of a large wind turbine tower due to fatigue failure of circumferential welded joints (Bild, 2014). In common tower finite element models the structures are simulated as full structures and there is no additional detail added in numerical models, which after recent accidents due to welding failure has to be reconsidered.

The circumferential and longitudinal welds shown in Fig. 1 are realized in order to connect subsequent tower subsections.

Tubular steel wind turbine towers are usually constructed by connecting tubular sections of about 20$30 \mathrm{~m}$ long on site by means of bolted flanges with the use of pretensioned bolts. These subsections are manufactured in the factory by rolling steel plates, of about $2.5 \mathrm{~m}$ wide, into a slightly tapered circular shape and welding them with a seam lengthwise to constitute a closed ring. The rings are connected with a circumferential welding seam to constitute a tower subpart, as it can be observed in Fig. 1 and its structural detail is depicted in Fig. 2.

The tower subparts of about $20 \mathrm{~m}$ long are welded at their edge to a circular flange of greater thickness than the tower shell as it can be observed at Fig. 3 later in the present document.

The concept of constructing a tower carrying great dead loads at elevated heights that are also moving gathers great bending moments at the bottom of the cantilever that are falling off towards the top of the tower. This load distribution along with the need for minimizing material consumption necessitates the construction of the tower as a truncated cone with cross-section diameters and shell thicknesses increasing from top to bottom. The truncated cone is constructed by welding consequent circular steel rings and the design of this connection type is important to be realized with focus on its response towards fatigue as accident reports' statistics highlight the importance of the fatigue assessment of welded joints. Indicatively, $12 \%$ of the overall number of accidents is attributed to structural failure and $6.8 \%$ is due to material fatigue (Chou and $\mathrm{Tu}, 2011$ ).

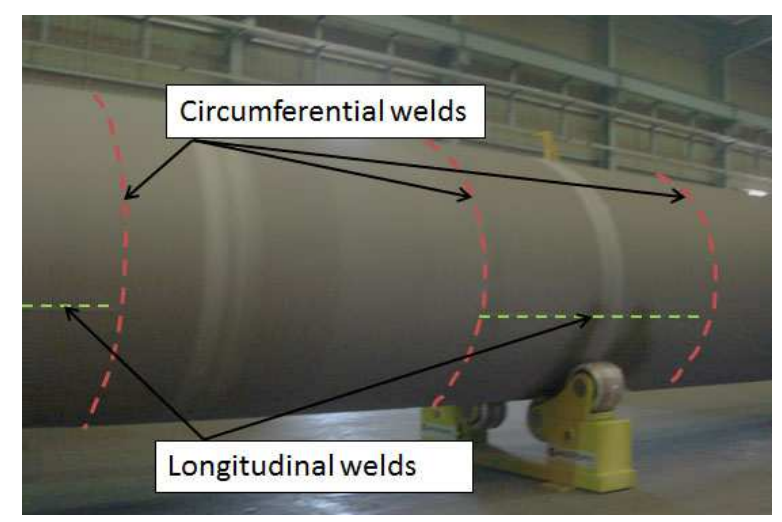

Fig. 1. Welds' positioning on wind turbine towers

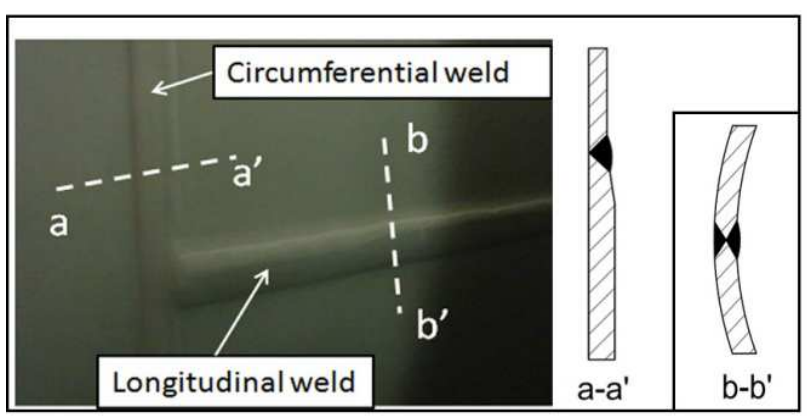

Fig. 2. Longitudinal and circumferential weld detail

\section{Structural Details}

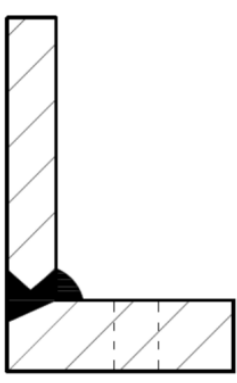

FLANGE

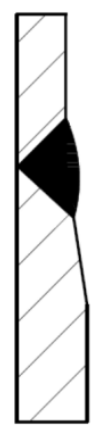

WELD
Fig. 3. Structural details investigated

Failures and cracking of welded joints have led Lacalle et al. (2011) to probe the causes of such damages in wind turbine towers. According to the same work, fatigue loading and inadequate weld design is very often the reason of remarkable stress concentrations around the weld seams and assiduous analyzes using different methods have been performed in order to assess the reliability of each methodology. In Nussbaumer et al. (2011) design guidelines it is stated that discontinuities 
in the material and joint geometry, holes, bolts and welds lead to concentration of stresses and possibly on fatigue problems. In discontinuities like thickness-transition cross-sections, eccentricities cause an increase in residual stresses due to local bending. Lotsberg (2009) assesses the reliability of reduction factors proposed in literature for fatigue design of butt welds after comparing analytical results with refined finite element analyses. The fabrication of the welds can often introduce material discontinuities, especially when connecting parts with great thicknesses, since defects with uncertain structural consequences can be provoked. Cicero et al. (2009) applied a methodology to assess the structural integrity of wind turbine towers where lacks of penetration defects were detected in circumferential welds. The relation of the structural integrity of structures and the defects was discussed in the same work and predictions of similar structures' behavior can be made. Another wind turbine tower structural detail that has to be taken care of is the bottom tower flange joint. The sharpness of the joint profile along with the thickness difference of the two connecting elements is proved numerically in the work of Lacalle et al. (2011) to provoke stress concentrations and internal tower cracking. The residual stresses developed in the welded connection between the lower tower part and the flange are calculated using welding temperature time histories and the influence of the geometry and fabrication of such joints is assessed in the work of Jiang et al. (2010). As it can be concluded from all the above mentioned scientific work, welded connections are vulnerable to fatigue loading and special attention has to be drawn when designing and constructing structures with many welded points. In order to limit the numerical investigation and fatigue design of such joints, an alternative bolded friction connection has been elaborated by Veljkovic et al. (2010), in order to replace the circumferential weld connecting subsequent steel rings in wind turbine tower construction. The fatigue results of the above mentioned connection were satisfactory but since its assembly is rather complicated, there is field for improvement before this solution is applied in industry.

Unlike the bottom flange weld, circumferential welds of wind turbine towers are very rarely investigated against fatigue loading since industry often neglects their precise calculation and practices the increase of the tower shell thickness in order to avoid the fatigue check. In steel wind tower fatigue analysis damage accumulation methods are used and it is often considered crucial to investigate all welds and bolts since structural details are proved to be more prone to fatigue. Since limited work has been devoted to the investigation of circumferential butt welds connecting subsequent tower parts the present work focuses on the investigation of the fatigue life of wind turbine towers depending on the assessment of circumferential welds.
Fatigue design has very strict requirements for welds and therefore all welds realized in wind turbine towers are designed as full penetration butt welds of high quality (Stathopoulos and Baniotopoulos, 2007). Weld fatigue life is estimated with the use of damage accumulation methods. European Standard provisions (EC, 2005a) determine the design resistance of a full penetration butt weld, when welding is performed according to applicability provisions, as the design resistance of the weaker of the parts connected. Therefore, in wind turbine tower structural analysis, macroscopic numerical models are used and the structure is simulated as a full sized tower with no special modelling of welds.

The present work aims to enlighten weld design procedures of wind turbine tower circumferential welds, through life cycle assessment, using damage accumulation methods. Two identical towers, whose structural analysis has been addressed in the thesis of Bzdawka (2011), are taken into account and their fatigue analysis is performed in the current paper. The towers differ in terms of shell thickness distribution along the height, since the initial constructed tower was overdesigned and the objective of the Master Thesis was to optimize the shell thickness distribution in order to minimize the amount of material used. The methods used in the present work calculate the damage accumulation at certain points. For the purposes of assessing the fatigue life of welded joints in wind turbine towers, two types of welding details are investigated in the present work and are shown in Fig. 3.

The first is the circumferential weld connecting the tower shell to the circular flange, named as FLANGE hereafter and the second is the circumferential weld connecting consequent tower rings in order to constitute a tower subpart, named as WELD hereafter. For the investigation described finite element analysis of the towers is performed with the aid of the commercial software ABAQUS (DS, 2012). The fatigue life of the structures is calculated with the damage accumulation method and more specifically the Palmgren-Miner rule. The loads for the fatigue assessment are obtained following two methods. In the first method, the loads are calculated from the analytical formula provided in Eurocode 1991-1-4 (EC, 2005b) for variant number of cycles of load recurrence. In the second method, timehistory loading data are used for the calculation of the towers' fatigue life. Instead of experimental wind data that are very often used for the fatigue assessment, artificial wind time-histories produced by National Renewable Energy Laboratory (NREL, 2015) and National Wind Technology Center (NTWC, 2015) software are used for the present investigation. The loading time histories are produced for different wind mean speeds by TurbSim (Kelley and Jonkman, 2012), Aerodyn (Laino, 2013) and FAST (Jonkman, 2005) software. The same software is used for the production of loading time histories that are employed 
for the fatigue assessment of bolted connections in the work of Thanasoulas et al. (2014). Stress spectra are produced with the use of Rainflow cycle counting method. Comparative results of the implementation of the two methods on the tower models are discussed. Useful conclusions have been derived from the comparative study, on the determination of the tower shell thicknesses and on the effect of fatigue loading towards the material amount used for the construction of the towers. Important remarks on the effect of fatigue loading of structures subjected to dynamic loading are stated.

\section{Fatigue Analysis}

\section{Fatigue Phenomenon}

The phenomenon when a material is weakened due to repeatedly applied loads, a fact that can be observed by the propagation of localized cracks at the region of stress concentration, is called fatigue. This type of material damage is noted even when the nominal maximum stress amplitude is within the elastic range of the material and usually beyond the material ultimate tensile stress limit. The material is subjected to repeated loading and unloading, microscopic cracks begin to arise at the stress concentration areas, they propagate suddenly and the results of the phenomenon can be disastrous with structures collapsing without prior notice. The process is rather unpredictable, showing scatter even under controlled conditions. In shell structures, discontinuities like shell thickness changes, holes, sharp edges, temperature, residual stresses, surface finishing, presence of chemicals etc. along with the loading cycles play a vital role when performing fatigue analysis. Wind turbine towers have to be reassured against the phenomenon since the stresses are repeatedly applied and relaxed by the resonant motion of the structure due to wind loading. The mother material of the tower very rarely suffers from fatigue failure, whereas details like local connections, welds, bolts and shell thickness variations are more vulnerable to developing failures related to fatigue loading and have to be addressed with special attention since they are crucial for the fatigue life calculation of the global structure. The endurance of wind turbine towers can be assessed by the calculation of the fatigue life of the structure. Fatigue life is defined as the number of stress cycles of a specified character that a structural detail can sustain before failure occurs. The damage of the structures is cumulative and the material does not recover when it is unloaded. Due to the cyclic loading, steel hardening occurs and the material becomes brittle, often leading to cracks and sudden collapses of the structures themselves without prior large deformation occurrence. For steel specifically, there is a theoretical stress amplitude value, called endurance limit, below which the material will not fail independently of the number of cycles it is loaded.

\section{Materials and Methods}

One of the methods that fatigue assessment can be performed is the damage accumulation method (EC, 2003) and the calculation procedure is prescribed in Annex A of the same document. The loading events that are taken into account in the method are based on prior knowledge obtained from similar structures, in order to represent a credible upper bound of the expected loading that the structure is going to be subjected to.

In the present scientific work two different methods are followed, assessed and compared. The damage accumulation calculation is the case in both methods, but loading is taken into account following different methodologies. In Method A the stress histories at the structural details under investigation are obtained from artificial loading time histories applied at the finite element model. In Eurocode provisions (EC, 2003) it is prescribed that stress histories are determined from measurements on similar structures or from dynamic calculations of the structural response. Since experimental data are often difficult to obtain and they differ significantly even between seemingly similar structures, artificial loading has the advantage of being cheaper and comparably accurate for such structures. In Method A a preliminary static analysis is conducted in order to determine the structural details that the above mentioned fatigue assessment will take place. This preliminary investigation is a simple linear static analysis that is conducted separately on both towers compared in the present study and the loads applied are the operational loads provided from the nacelle manufacturer. In more detail, the loading applied on the tower finite element models consists of the loads that are considered more important for the fatigue assessment; a horizontal force and an overturning moment due to the wind turbine operation. The structural details at which the fatigue life assessment is carried out are separately chosen for each tower as the point belonging to the circumferential weld connecting shell parts and a point at the circumferential weld connecting the tower shell with a flange, where the highest normal stress concentration is observed. In this method, after the points with the highest stress concentration are chosen from the preliminary analysis for both towers under investigation, loading time histories of different wind mean speeds are applied at the finite element model. The stress time-histories at the structural details of each tower are obtained and they are the primary data on which fatigue analysis is based. The rainflow cycle counting method is chosen in order to convert the complex stress time histories into simple cyclic loadings or stress range spectra. The result of the rainflow counting method can be transformed into a spectrum of amplitudes of stress cycles in one year. After the calculation of the amplitude spectrum, the linear damage accumulation method is used in order to calculate the fatigue life of the structure. 
In the second method used in the present work the load is not taken into account as artificial or real time history. The stress level at the relevant structural detail is obtained from a linear static analysis with a percentage of the load of the one with a return period of 50 years. This percentage of stress level is assigned a number of load repetitions from the analytical Equation 1:

$$
\frac{\Delta S}{S_{k}}=0,7 \times\left(\log \left(N_{g}\right)\right)^{2}-17,4 \times \log \left(N_{g}\right)+100
$$

Where:

$\Delta S=$ The stress range $(\mathrm{MPa})$

$S_{k}=$ The stress due to a 50 years return period wind (MPa)

$N_{g}=$ The number of loads

The stress level $\mathrm{S}_{\mathrm{k}}$ is calculated in the preliminary analysis of the two towers. After having obtained the stress levels achieved for the assigned number of loads and after having chosen the relevant structural detail category from Eurocode Tables (EC, 2003) the loading cycles corresponding to the fatigue strength are obtained. The loading cycles are calculated for each stress level, from Equation 2 and 3:

$$
\begin{aligned}
& N_{i}=\left(\frac{\Delta \sigma_{c}}{\Delta \sigma_{i}}\right)^{\mathrm{m}} \cdot 2 \cdot 10^{6}, \text { with } m=3 \text { for } N \leq 5 \cdot 10^{6} \\
& N_{i}=\left(\frac{\Delta \sigma_{c}}{\Delta \sigma_{i}}\right)^{\mathrm{m}} \cdot 5 \cdot 10^{6}, \text { with } m=5 \text { for } 5 \cdot 10^{6} \leq N \leq 10^{8}
\end{aligned}
$$

Where:

$\Delta \sigma_{c}=$ The fatigue strength at 2 million cycles (MPa)

$\Delta \sigma_{i}=$ The stress range due to a 50 years return period wind $(\mathrm{MPa})$

Having defined the detail category (S-N curve) for the details under investigation, the damage of the structures can be calculated by applying the linear damage accumulation method, in practice called Palmgren-Miner rule. The cumulated damage is given in Equation 4:

$$
D_{d}=\sum_{i}^{n} \frac{n_{E i}}{N_{i}}
$$

Where:

$n_{E i}=$ The number of cycles associated with the stress range $\gamma_{F f} \Delta \sigma_{i}$ for band $i$ in the factored spectrum

$N_{i}=$ The endurance (in cycles) obtained from the factored curve or from Equation 2 and 3

The reciprocal value of the damage equals the approximated lifetime of the steel tower. In the case of Method A, $n_{E i}$ is calculated from the annual stress spectrum, while in Method B it is the number of loads for dynamic response that is assigned to each stress percentage from Equation 1.

\section{Finite Element Analysis}

In the present investigation, a comparative study of the fatigue life calculation of two $76.15 \mathrm{~m}$ hub height wind turbine towers is carried out. The tower height and their shell thickness distribution are presented in Fig. 4. Tower-1 has been introduced and analyzed by Veljkovic et al. (2006) and its structural behavior has been verified in the Thesis of Bzdawka (2011), while Tower-2 has been the attempt of the latter to reduce the material used for the tower construction, preserving the tower behavior to acceptable levels. Both of the towers comply with certain restrictional transportation requirements concerning maximum top diameter and maximum tower part length. The maximum length of the tower sections is usually governed by requirements to allow for transportation while the upper limit for the outer diameter of land-based wind turbine towers is usually governed by restrictions imposed by the maximum clearance under highway bridges.

The conventional maximum value for the top tower diameter provided by the manufacturer is defined as 3.0 $\mathrm{m}$ and the maximum bottom diameter is defined as $5.0 \mathrm{~m}$ while the maximum length of a transported element is usually around $25 \mathrm{~m}$ long and never exceeding $30 \mathrm{~m}$. Following the above mentioned restrictions imposed by the manufacturer and by design codes, the towers under investigation consist of subsections of $2.2 \mathrm{~m}$ height and only the top section is set to $2 \mathrm{~m}$ in order to complete the full tower length. The top diameter is $3.0 \mathrm{~m}$ and the bottom one is $4.3 \mathrm{~m}$. Both towers have been designed under extreme wind conditions and additional criteria for shell thicknesses are investigated in order to minimize the tower mass in the scientific work conducted by Bzdawka (2011).

\section{Materials and Loads}

The two towers under investigation are steel tubular wind turbine towers. The material of the towers is S355 and since in all the analyses the stress levels remain at the elastic range, no hardening is taken into account in the material law and a simple stable plateau is only used in case some elements enter plasticity.

As it has already been discussed, the static loads incorporated in the linear static preliminary analysis of the towers are simple operational loads due to the function of the turbine and are provided by the manufacturers of the machinery. Since the rotor and blades that the towers have to support are the same, the loads applied are common and are: the horizontal force of $\mathrm{F}=75.5 \mathrm{kN}$ and the horizontal axis moment of $\mathrm{M}=$ $1091 \mathrm{kNm}$. The tower weight is not taken into account in the fatigue analysis. 
For the numerical analyses conducted in the frame of Method A, the loading time-histories are produced with the aid of NREL and NTWC freeware; Turbsim, Fast and Aerodyn and for time and data saving reasons only the two major loading histories at the top of the tower are taken into account. The time-histories correspond to variable mean wind speeds in order to cover all the spectrum of operational winds. There are 6 time-histories produced at the towers' hub height for a wind of turbulence level B and according to Kaimal frequency spectrum, for mean wind speeds of 2, 6, 10, 14, 18 and $22 \mathrm{~m} / \mathrm{sec}$. The horizontal wind velocity time-histories are presented in Fig. 5 for the above mentioned mean wind speeds. The loading histories are applied at the tower hub height to a reference point eccentrically located simulating the exact rotor position. This position is shifted horizontally $+0.725 \mathrm{~m}$ from the axis of the tower and vertically $+0.50 \mathrm{~m}$ above the upper flange level (+76.15 m).

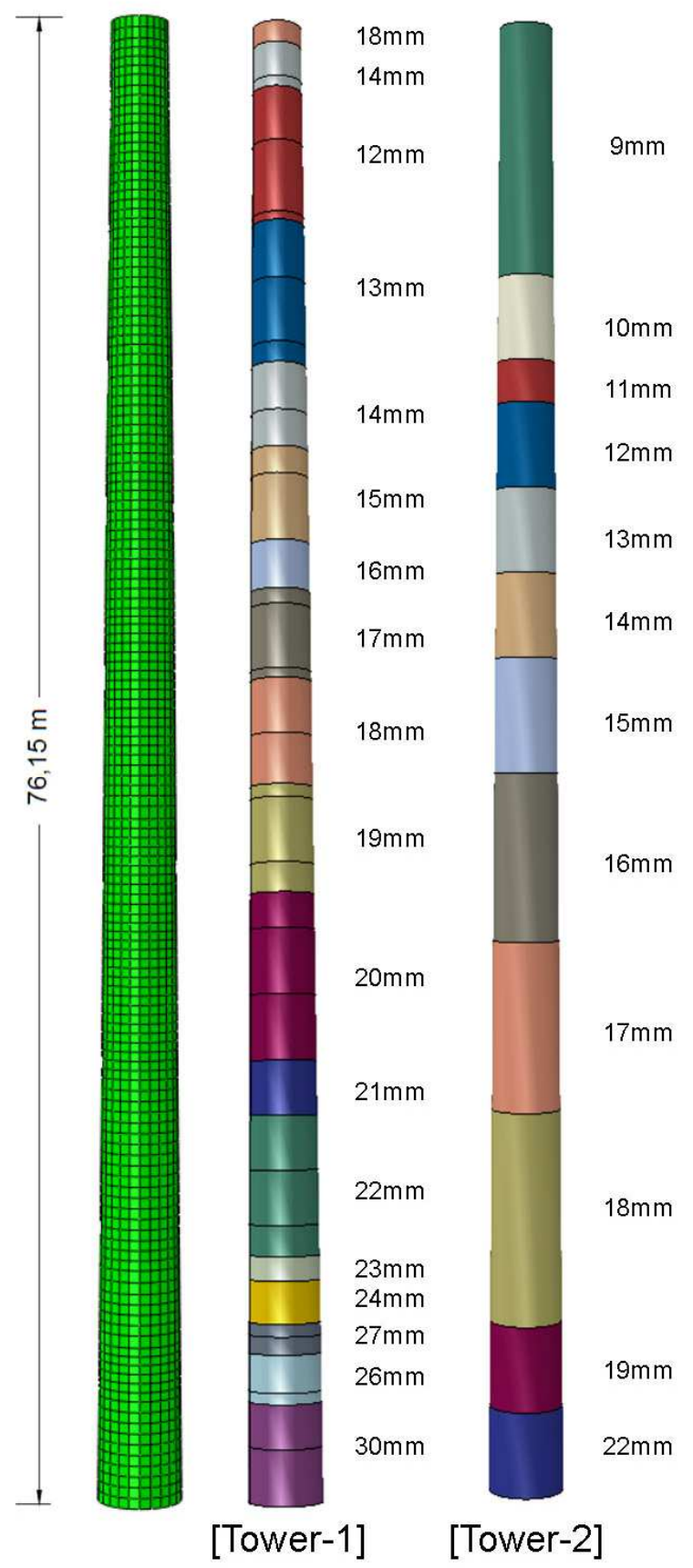

Fig. 4. Shell thickness distribution for Tower-1 and Tower-2 

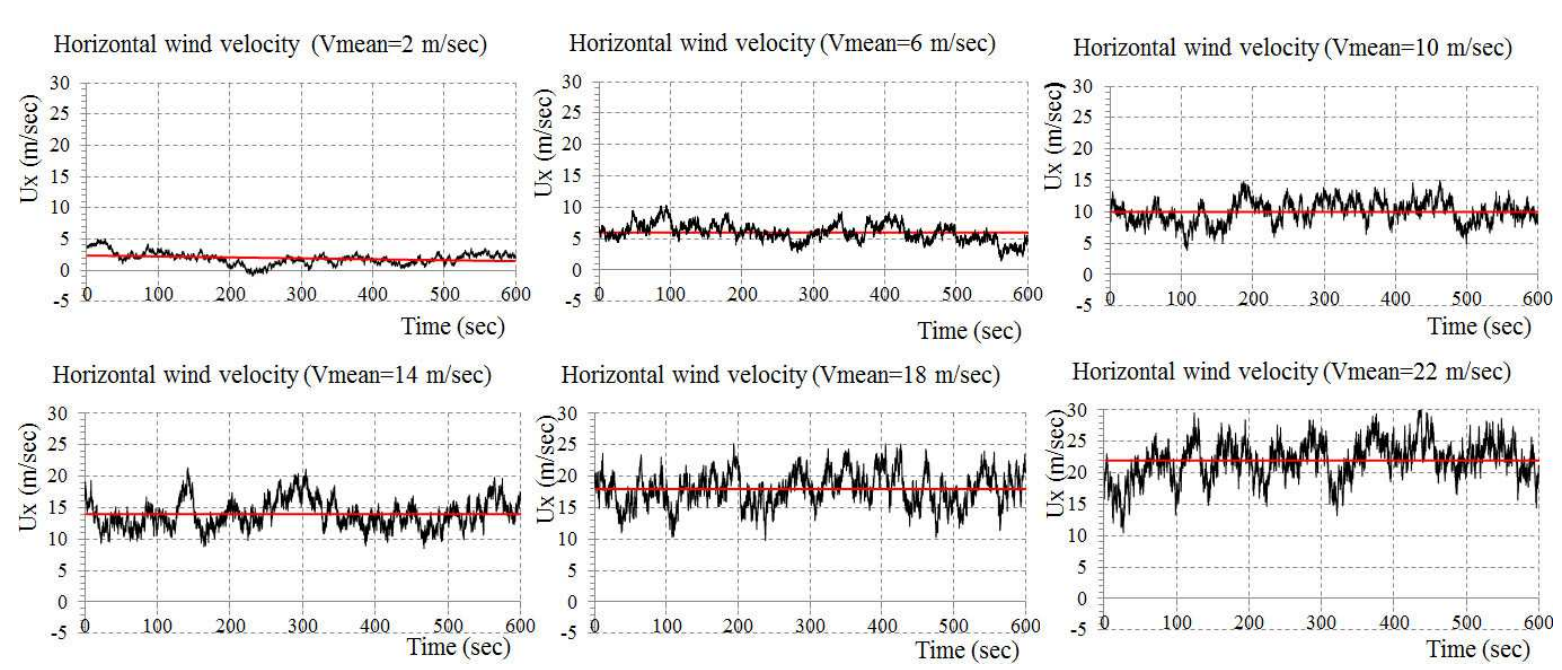

Fig. 5. Horizontal wind velocity acting at the tower hub height for different values of wind mean speed

\section{Results}

\section{Method A (Time-History) Results}

The basic parameter that has to be calculated in order to perform the fatigue life assessment is the stress history $\sigma_{\mathrm{zz}}$ at the structural details under consideration, deriving from the effect of the artificial time histories applied. The normal stresses of the tower shell are obtained from numerical analyses of the two towers and the results for the two structural details and for variant mean wind speeds are presented in Fig. 6 and 8 for Tower- 1 and in Fig. 7 and 9 for Tower-2.

The stress histories at the preferred structural detail are evaluated by following the rainflow cycle counting method in order to determine the stress ranges and their number of cycles and the stress range spectra for both towers are presented in the following figures. In Fig. 10 and 12 the stress range histograms for detail WELDTower-1 and FLANGE-Tower-1 respectively are presented and in Fig. 11 and 13 the stress range histograms for detail WELD-Tower-2 and FLANGETower-2 are presented.

The stress range histograms are more useful than the stress histories because the latter are time-related and great variability of frequencies and ranges are observed. The complex stress time histories are converted to histograms of number of cycles and stress levels by converting the simple time history to simple cyclic loading and picking the peaks for tensile and the valleys for compressive stresses through the rainflow method. This is realized by applying the relevant code in matlab software.

The stress range spectra presented above associate the stress ranges and the relevant number of cycles in descending order. The stress level histograms of the structural details obtained from the preliminary analysis are produced for each one of the six wind speed time histories as shown in Fig. 10-13. The fatigue check is referring to normal operating conditions, so the first 10 seconds of the loading time histories are neglected in the analysis due to the presence of signal noise deriving from the launching of the machinery. The above presented stress range histograms refer to the annual number of cycles for each stress level based on the number of cycles in the $10 \mathrm{~min}$ wind. In order to calculate the fatigue life of the towers, the stress range histograms of each wind mean speed have to be combined to constitute the annual stress range histogram. The annual number of cycles of the histogram derives from the sum of the cycles of each $10 \mathrm{~min}$ wind multiplied by the relevant probability of occurrence, multiplied by the number of 10 minute durations in one year. According to IEC 61400-1 (IEC, 2005) the distribution of wind speeds over an extended period of time is given by the Rayleigh or the Weibull distribution. In the present study the Rayleigh distribution is used in order to calculate the probability of occurrence of each stress level. The probability density function and the cumulative density function of the Rayleigh distribution are presented in Fig. 14.

Taking into account the probability of occurrence calculated from the Rayleigh distribution and the annual stress range histograms for each wind mean speed, the annual stress range spectrum for each tower is calculated and presented in Fig. 15-18.

As it has already been explained in the introduction of the present work damage due to fatigue is cumulative and the material does not recover when it is unloaded. For this damage calculation the assumption of linear damage accumulation is taken into account and the Palmgren-Miner rule is followed. The linear damage accumulation scheme assumes that stress ranges, occurring $n_{i}$ times results in a partial damage that is represented by a ratio $n_{i} / N_{i}$ where $N_{i}$ is the number of cycles to failure. 

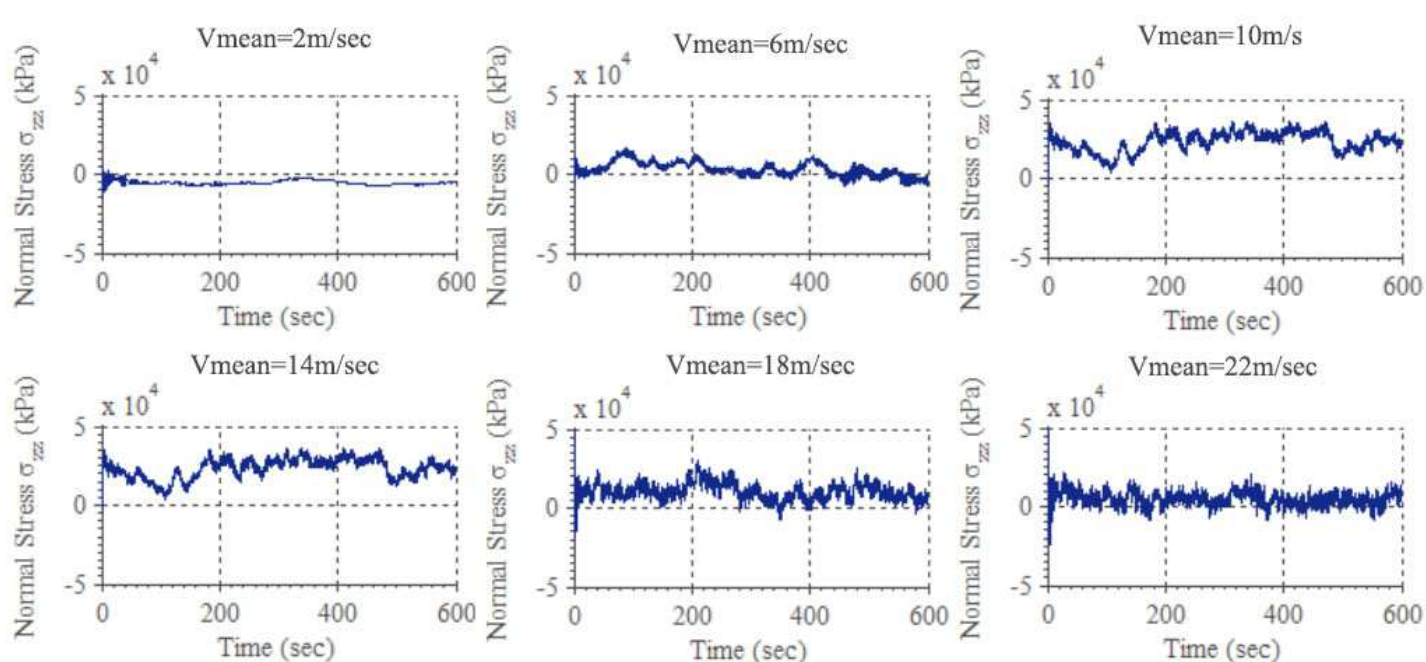

Fig. 6. Tensile stress history of detail type WELD-Tower-1 for variable mean wind speeds
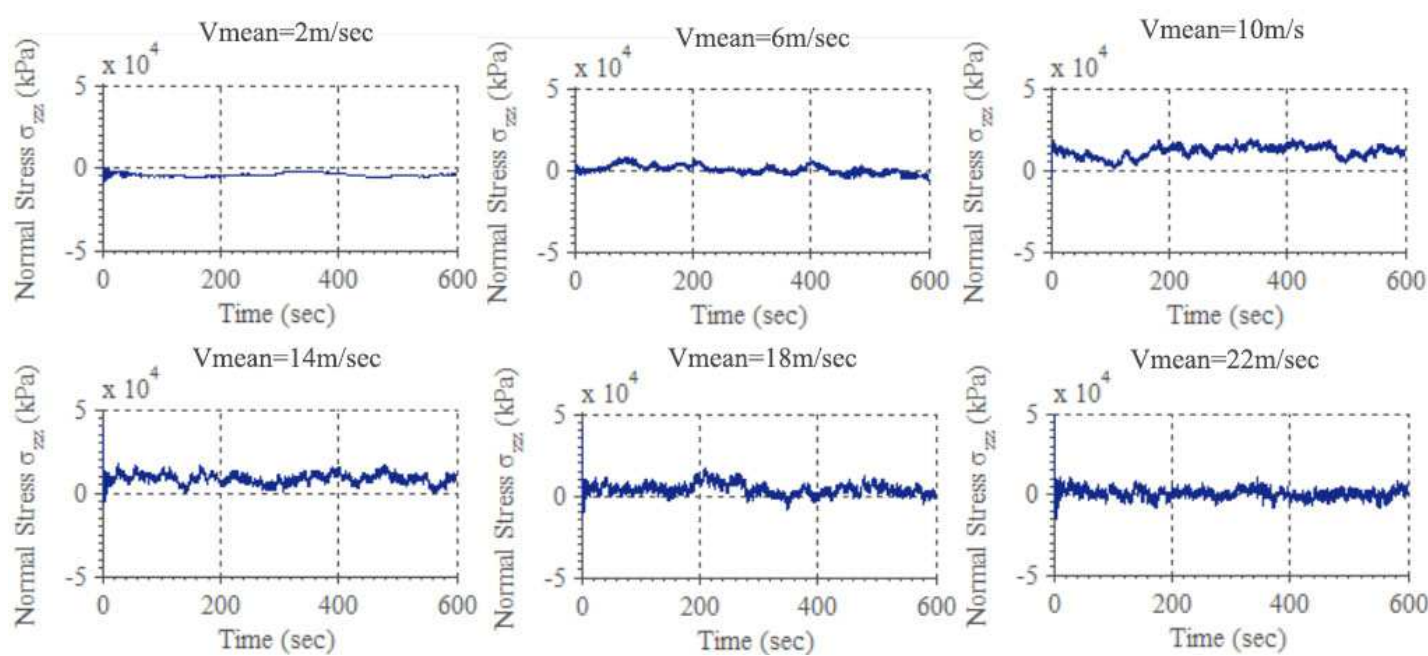

Fig. 7. Tensile stress history of detail type WELD-Tower-2 for variable mean wind speeds
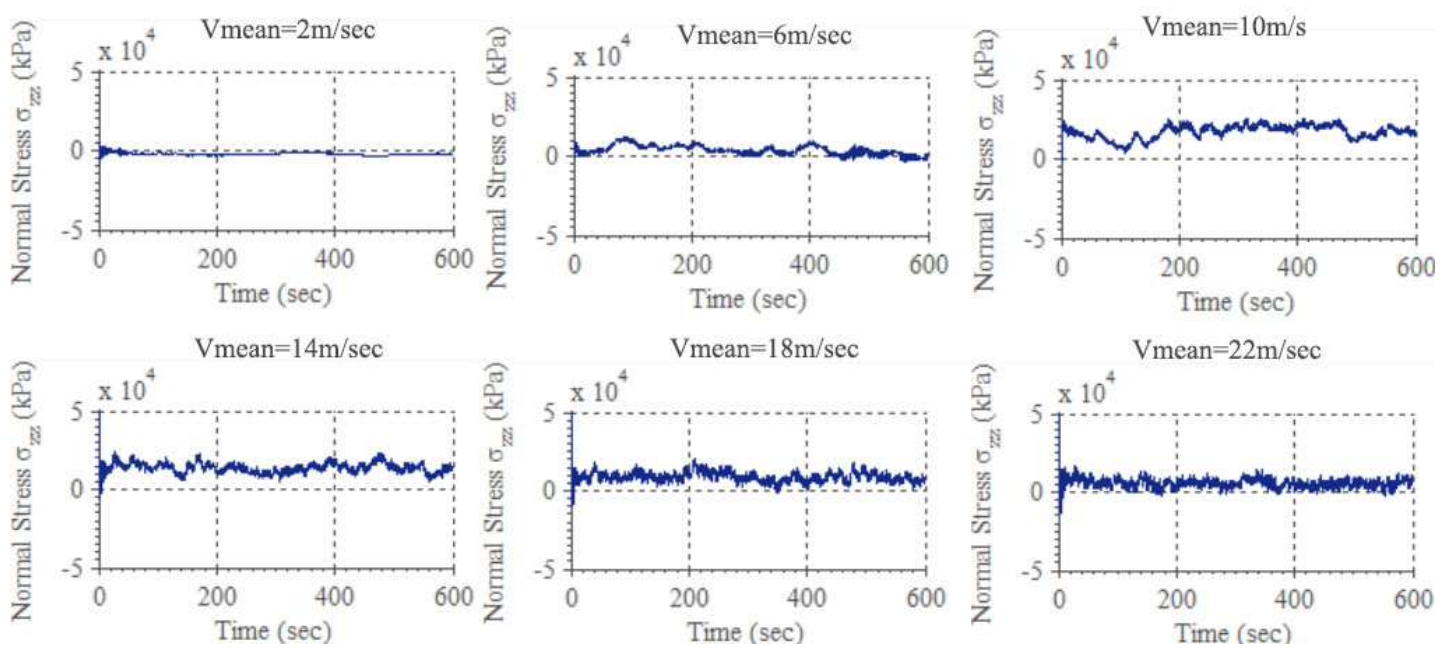

Fig. 8. Tensile stress history of detail type FLANGE-Tower-1 for variable mean wind speeds 

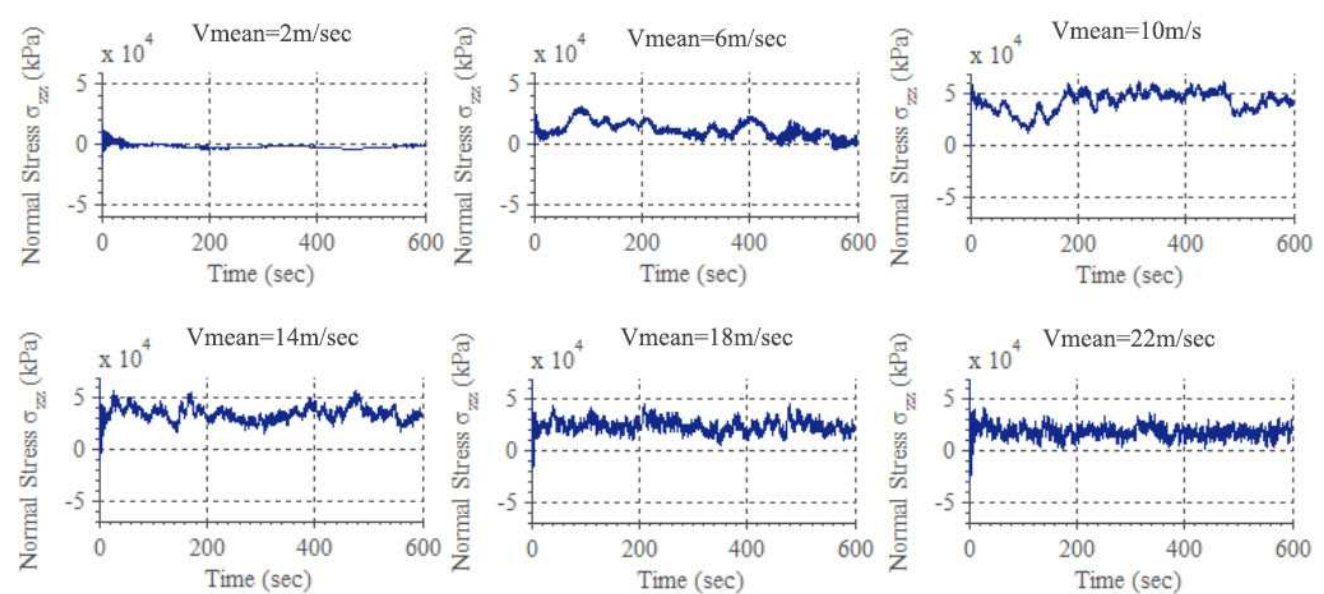

Fig. 9. Tensile stress history of detail type FLANGE-Tower-2 for variable mean wind speeds


Fig. 10. Stress range histograms for detail WELD-Tower-1 for variable mean wind speeds
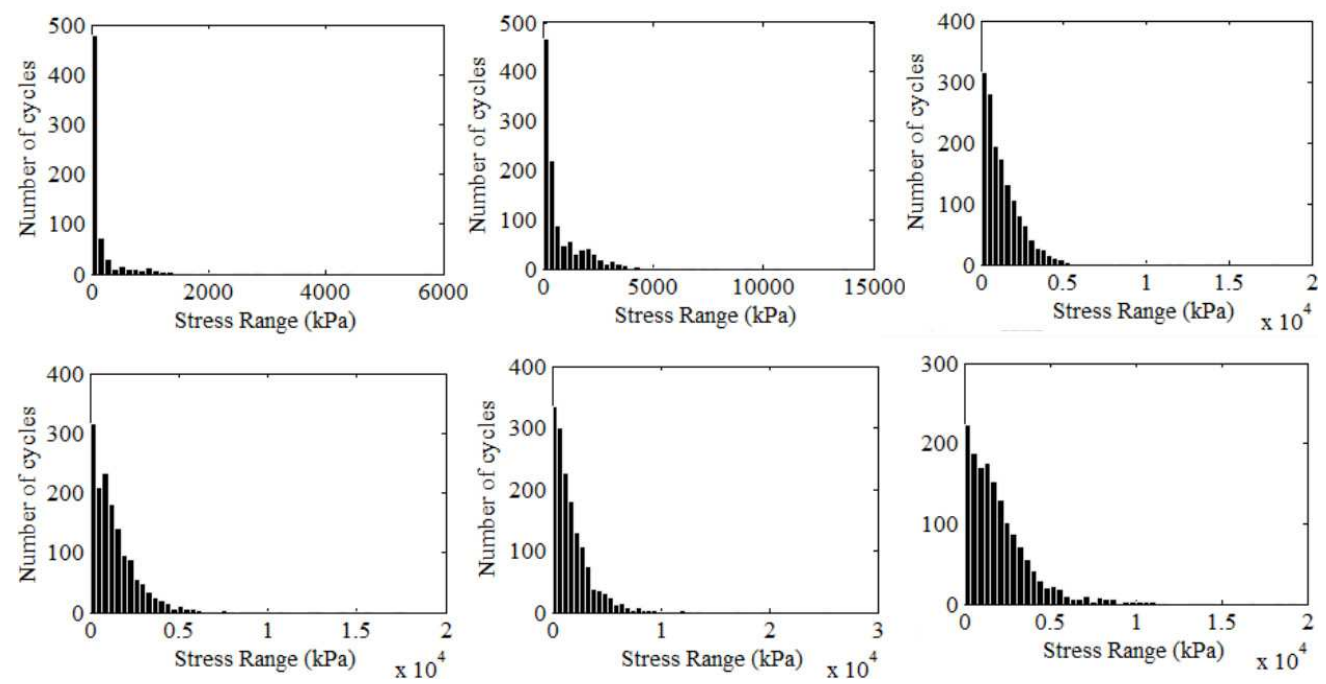

Fig. 11. Stress range histograms for detail WELD-Tower-2 for variable mean wind speeds 

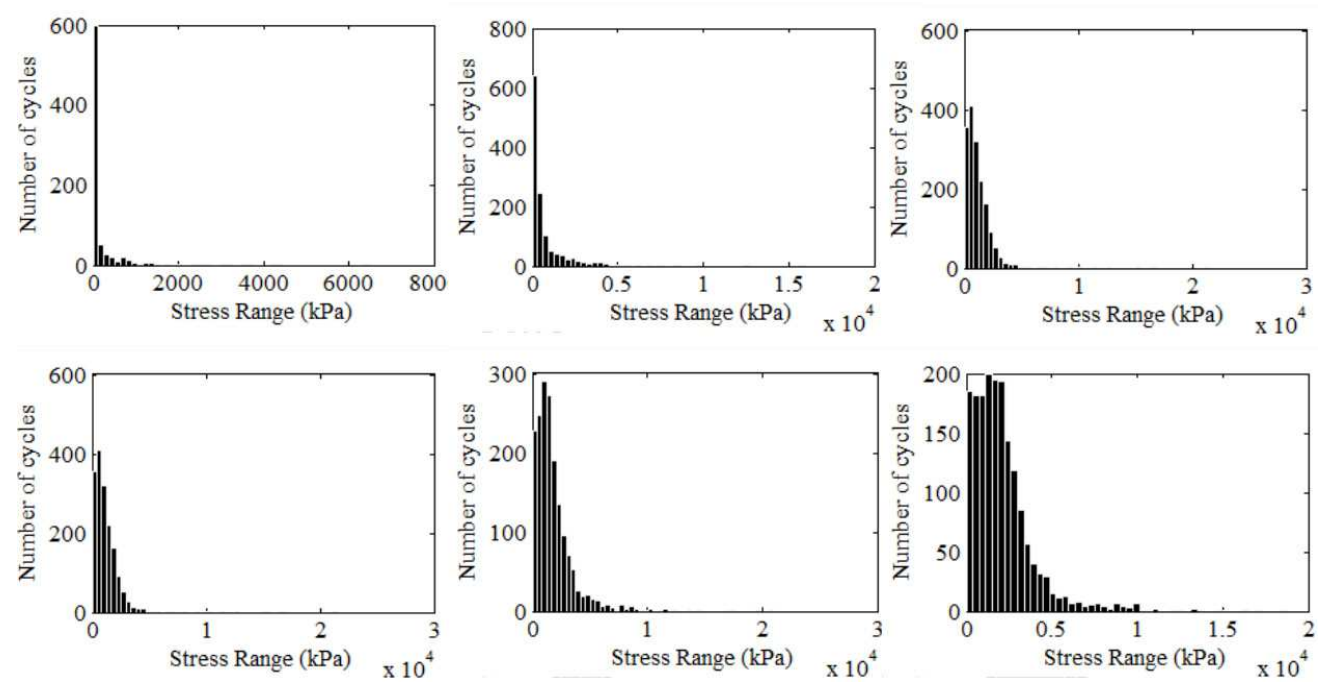

Fig. 12. Stress range histograms for detail FLANGE-Tower-1 for variable mean wind speeds
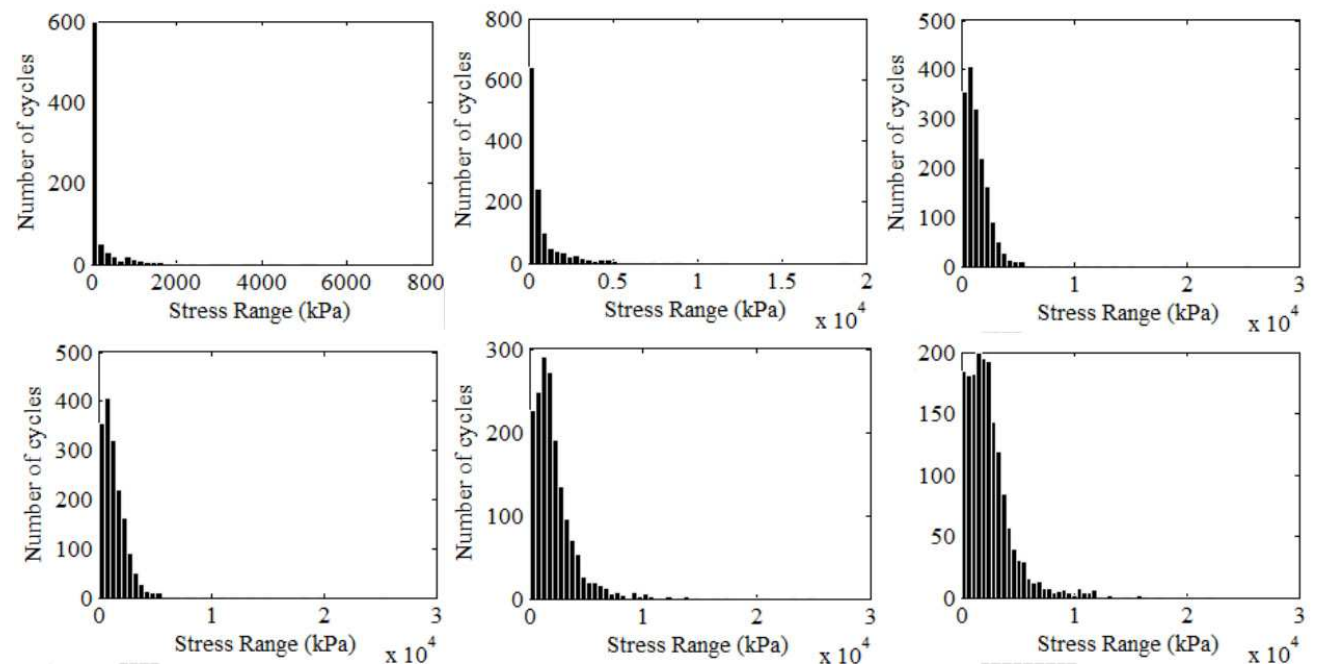

Fig. 13. Stress range histograms for detail FLANGE-Tower-2 for variable mean wind speeds

Probability Density Function

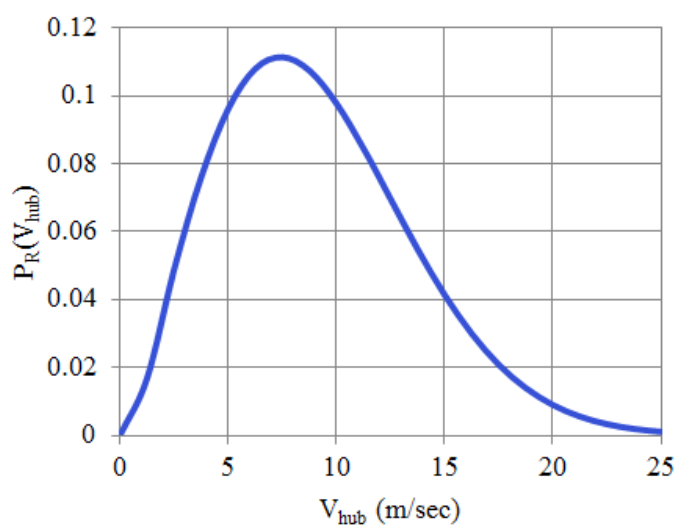

Cumulative Density Function

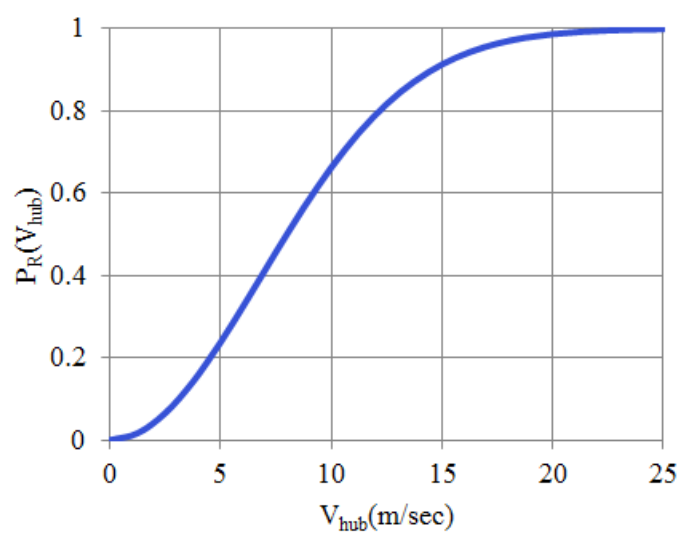

Fig. 14. Rayleigh distribution functions 




Fig. 15. Annual stress range histogram for WELD-Tower-1

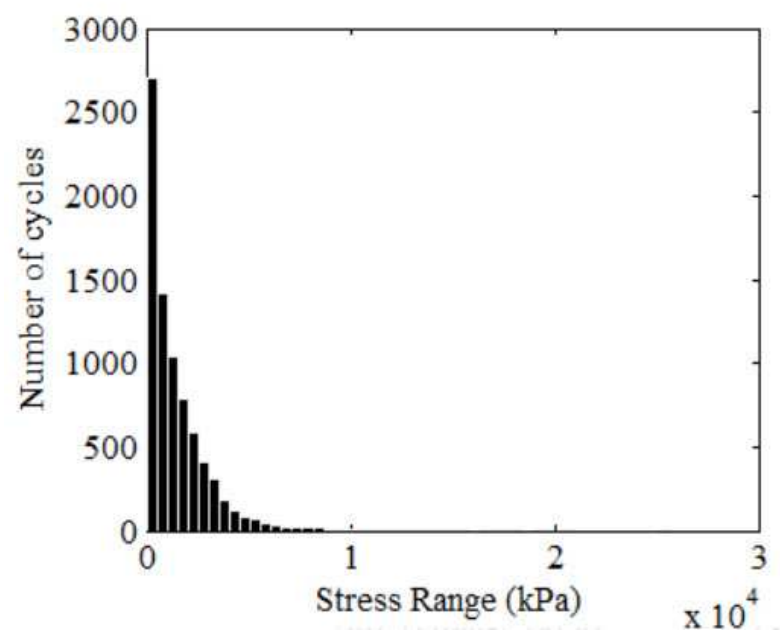

Fig. 16. Annual stress range histogram for WELD-Tower-2

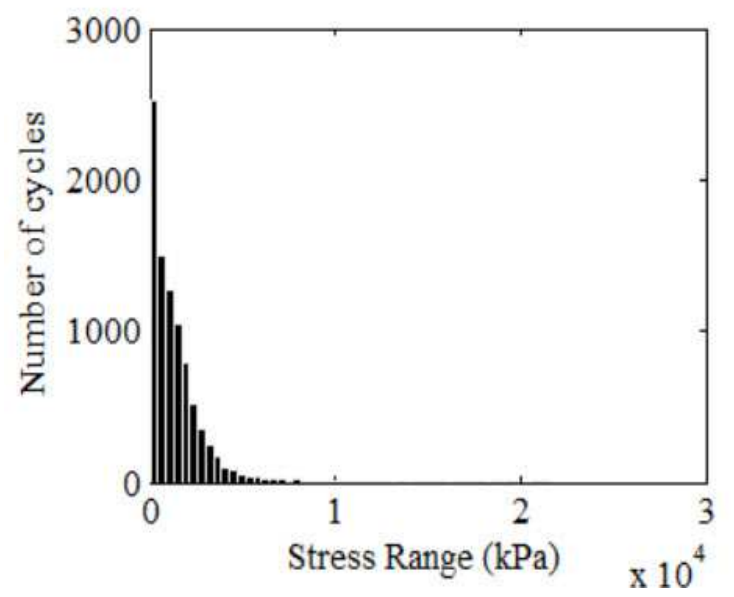

Fig. 17. Annual stress range histogram for FLANGETower-1

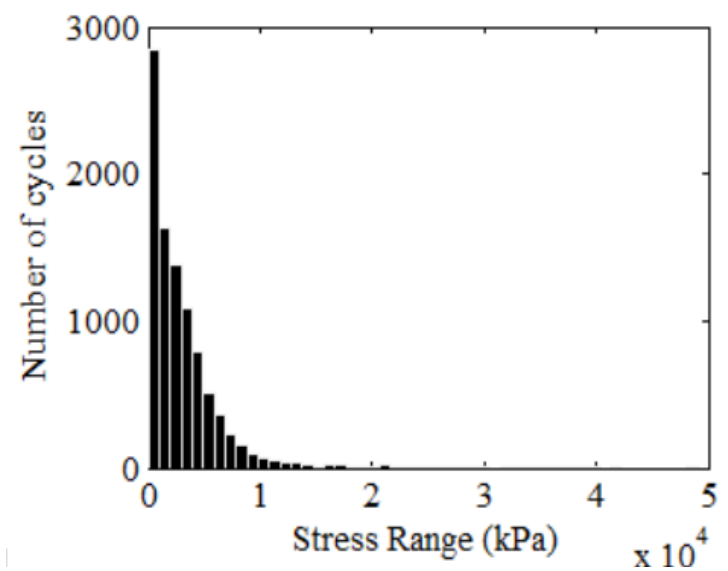

Fig. 18. Annual stress range histogram for FLANGETower-2

The failure of the detail is defined by the sum of all the partial damages. The detail category that corresponds to the circumferential weld between consequent tower parts, according to EN 1993-1-9 (EC, 2003) has fatigue stress capacity of $\Delta \sigma_{\mathrm{c}}=80 \mathrm{MPa}$, while the one that corresponds to the circumferential weld between the tower and the flange, according to the same document has fatigue stress capacity of $\Delta \sigma_{\mathrm{c}}=40 \mathrm{MPa}$. The factored capacity curve that corresponds to the first structural detail is presented in Fig. 19 while the one that corresponds to the latter, in Fig. 20.

The fatigue check of the structural details of the two towers using Methodology A implies that the cumulative damage $\mathrm{D}$ defined in Equation 4 should be lower than the theoretical value of 1 when damage occurs. The annual cumulative damage for Tower-1 when checking structural detail WELD is 0.0007 and for Tower- 2 is 0.0019 . For structural detail FLANGE, it is 0.0028 for Tower- 1 and 0.0082 for Tower- 2 . The fatigue check criterion is fulfilled for both towers and for all cases. For detail WELD, the fatigue life of the first tower is over 1000 years while for Tower-2 with smaller wall thicknesses falls about 500 years. This is indicative of the fact that both towers are well designed, since the fatigue criterion is fulfilled. With a small reduction in shell thicknesses, the total mass of the tower is reduced about $20 \%$, while the fatigue life is reduced by $50 \%$. For detail FLANGE, the fatigue life of Tower- 1 is calculated to 350 years, while for Tower-2 it is 120 years. Again the fatigue life of the structure is reduced more than $50 \%$ with a material reduction of $20 \%$. This shows that the shell thickness is a decisive factor for the fatigue life of the structure.

\section{Method B (Dynamic Load) Results}

The fatigue check of the structural details of the two towers with Methodology B is also following the damage accumulation criterion and only the way that the 
stresses at the structural details under consideration are calculated changes. In this method only simplified static analyses are conducted, since the loading of the structures is a single static load given by the manufacturer and the theoretical number of times (cycles) of occurrence of each load is associated through the analytical equation provided by Eurocode (EC, 2005a). The number of cycles leading to fatigue failure is indicative of each structural detail and is common between the two methods as presented in Fig. 19 and 20. The partial damage is calculated for each stress range and all the partial damages are summed again using the Palmgren-Miner rule. This calculation is presented in Table 1 for structural detail WELD and in Table 2 for structural detail FLANGE. When assessing the structural detail WELD, the annual cumulative damage for Tower- 1 is 0.0006 and for Tower- 2 is 0.0013 . The fatigue check criterion is again fulfilled for both towers showing that they are well designed. For structural detail FLANGE, the cumulative damage for Tower- 1 is 0.0045 while for Tower- 2 is 0.0082 . The fact that cumulative damage is greater in structural detail FLANGE in both methods is indicative that this weld type is more vulnerable to failure and special attention needs to paid in the tower design. The fatigue life of the towers is again calculated for the results of this methodology and is 2500 years for WELD-Tower-1 while for WELDTower-2 with smaller wall thicknesses falls to 700 years. The situation is similar to method A since FLANGE-Tower-1 presents fatigue life of 220 years while FLANGE-Tower-2 120 years.

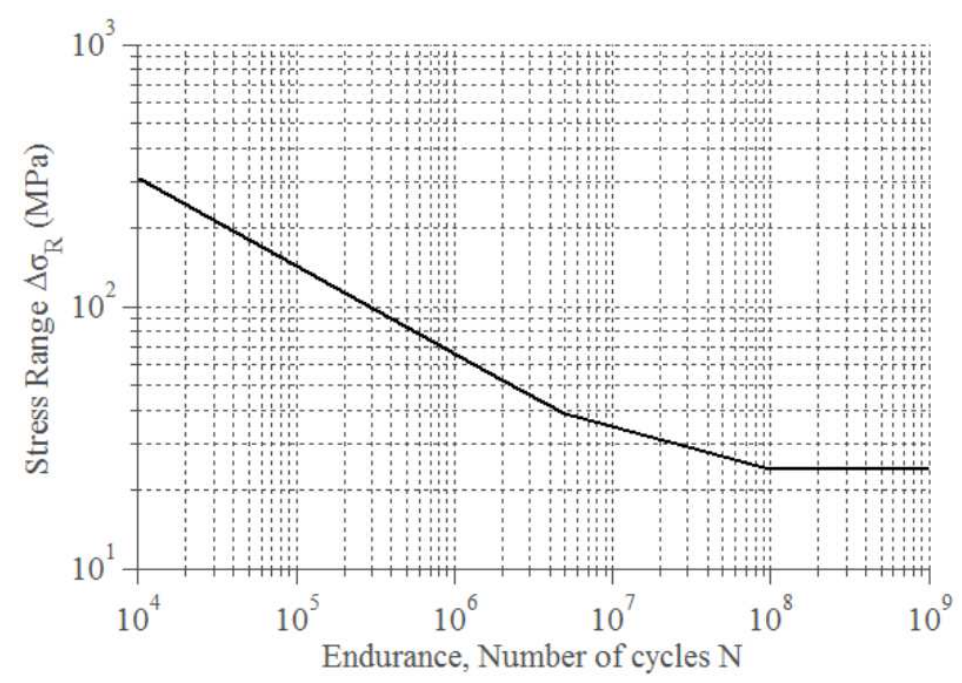

Fig. 19. Direct stress range over endurance for $\Delta \sigma=80 \mathrm{MPa}$

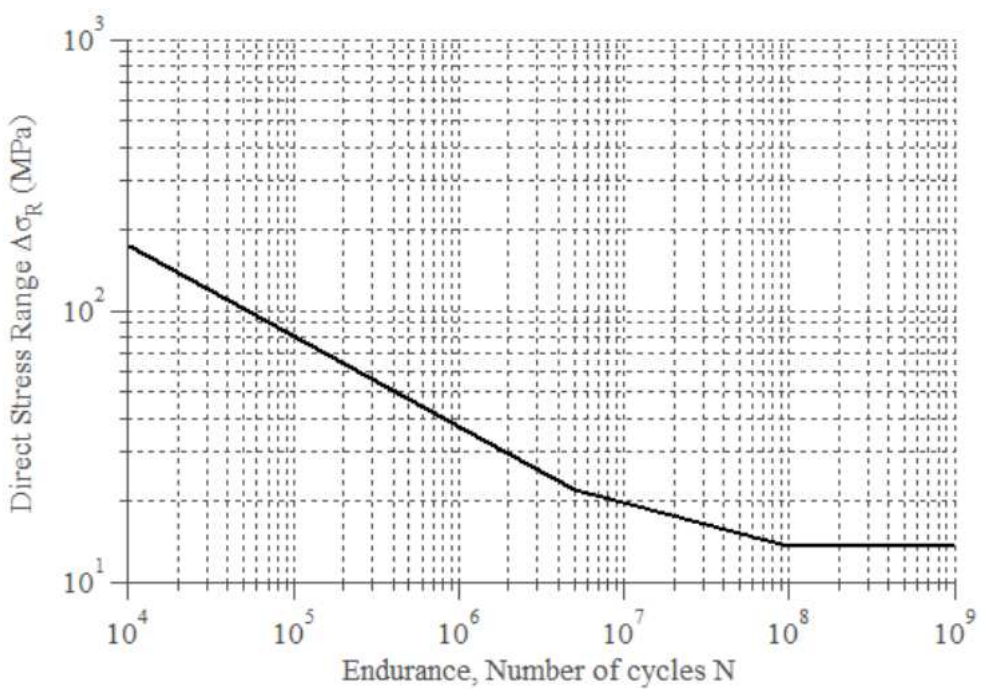

Fig. 20. Direct stress range over endurance for $\Delta \sigma=40 \mathrm{MPa}$ 
Table 1. Damage accumulation calculation for Method B for structural detail WELD

\begin{tabular}{|c|c|c|c|c|c|c|c|}
\hline \multirow[b]{2}{*}{$\underline{\mathrm{n}_{\mathrm{i}}}$} & \multirow[b]{2}{*}{$\Delta \mathrm{S} / \mathrm{S}_{\mathrm{k}}$} & \multicolumn{3}{|c|}{ Tower-1 } & \multicolumn{3}{|c|}{ Tower-2 } \\
\hline & & $\sigma_{\mathrm{i}}$ & $\mathrm{N}_{\mathrm{i}}$ & $n_{i} / N_{i}$ & $\sigma_{\mathrm{i}}$ & $\mathrm{N}_{\mathrm{i}}$ & $\mathrm{n}_{\mathrm{i}} / \mathrm{N}_{\mathrm{i}}$ \\
\hline 1 & 100.00 & 22.16 & $6.19 \mathrm{E}+07$ & $1.62 \mathrm{E}-08$ & 28.03 & $3.06 \mathrm{E}+07$ & $3.27 \mathrm{E}-08$ \\
\hline 5 & 88.18 & 19.54 & $9.02 \mathrm{E}+07$ & 5.54E-08 & 24.72 & $4.46 \mathrm{E}+07$ & $1.12 \mathrm{E}-07$ \\
\hline 10 & 83.30 & 18.46 & $1.07 \mathrm{E}+08$ & $9.34 \mathrm{E}-08$ & 23.35 & $5.29 \mathrm{E}+07$ & $1.89 \mathrm{E}-07$ \\
\hline 50 & 72.46 & 16.06 & $1.63 \mathrm{E}+08$ & $3.07 \mathrm{E}-07$ & 20.31 & $8.03 \mathrm{E}+07$ & $6.22 \mathrm{E}-07$ \\
\hline 100 & 68.00 & 15.07 & $1.97 \mathrm{E}+08$ & $5.08 \mathrm{E}-07$ & 19.06 & $9.72 \mathrm{E}+07$ & $1.03 \mathrm{E}-06$ \\
\hline 500 & 58.14 & 12.88 & $3.15 \mathrm{E}+08$ & $1.59 \mathrm{E}-06$ & 16.30 & $1.56 \mathrm{E}+08$ & $3.21 \mathrm{E}-06$ \\
\hline $10^{3}$ & 54.10 & 11.99 & $3.91 \mathrm{E}+08$ & $2.56 \mathrm{E}-06$ & 15.17 & $1.93 \mathrm{E}+08$ & $5.18 \mathrm{E}-06$ \\
\hline $5 * 10^{3}$ & 45.22 & 10.02 & $6.69 \mathrm{E}+08$ & 7.47E-06 & 12.68 & $3.31 \mathrm{E}+08$ & $1.51 \mathrm{E}-05$ \\
\hline $10^{4}$ & 41.60 & 9.22 & $8.59 \mathrm{E}+08$ & $1.16 \mathrm{E}-05$ & 11.66 & $4.24 \mathrm{E}+08$ & $2.36 \mathrm{E}-05$ \\
\hline $5 * 10^{4}$ & 33.69 & 7.47 & $1.62 \mathrm{E}+09$ & $3.09 \mathrm{E}-05$ & 9.45 & $7.99 \mathrm{E}+08$ & $6.26 \mathrm{E}-05$ \\
\hline $10^{5}$ & 30.50 & 6.76 & $2.18 \mathrm{E}+09$ & $4.59 \mathrm{E}-05$ & 8.55 & $1.08 \mathrm{E}+09$ & $9.28 \mathrm{E}-05$ \\
\hline $5 * 10^{5}$ & 23.57 & 5.22 & $4.72 \mathrm{E}+09$ & $1.06 \mathrm{E}-04$ & 6.61 & $2.33 \mathrm{E}+09$ & $2.14 \mathrm{E}-04$ \\
\hline $10^{6}$ & 20.80 & 4.61 & $6.88 \mathrm{E}+09$ & $1.45 \mathrm{E}-04$ & 5.83 & $3.40 \mathrm{E}+09$ & $2.94 \mathrm{E}-04$ \\
\hline $5 * 10^{6}$ & 14.85 & 3.29 & $1.89 \mathrm{E}+10$ & $2.65 \mathrm{E}-04$ & 4.16 & $9.33 \mathrm{E}+09$ & $5.36 \mathrm{E}-04$ \\
\hline $10^{7}$ & 12.50 & 2.77 & $2.00 \mathrm{E}+13$ & $5.01 \mathrm{E}-07$ & 3.50 & $6.17 \mathrm{E}+12$ & $1.62 \mathrm{E}-06$ \\
\hline $5 * 10^{7}$ & 7.53 & 1.67 & $2.52 \mathrm{E}+14$ & $1.98 \mathrm{E}-07$ & 2.11 & $7.77 \mathrm{E}+13$ & $6.43 \mathrm{E}-07$ \\
\hline \multirow[t]{2}{*}{$10^{8}$} & 5.60 & 1.24 & $1.11 \mathrm{E}+15$ & $9.03 \mathrm{E}-08$ & 1.57 & $3.42 \mathrm{E}+14$ & $2.93 \mathrm{E}-07$ \\
\hline & & & $D_{d}=$ & 0.0006 & & $D_{d}=$ & 0.0013 \\
\hline
\end{tabular}

Table 2. Damage accumulation calculation for Method B for structural detail FLANGE

\begin{tabular}{|c|c|c|c|c|c|c|c|}
\hline \multirow[b]{2}{*}{$\underline{\mathrm{n}_{\mathrm{i}}}$} & \multirow[b]{2}{*}{$\Delta \mathrm{S} / \mathrm{S}_{\mathrm{k}}$} & \multicolumn{3}{|c|}{ Tower-1 } & \multicolumn{3}{|c|}{ Tower-2 } \\
\hline & & $\sigma_{i}$ & $\mathrm{~N}_{\mathrm{i}}$ & $\mathrm{n}_{\mathrm{i}} / \mathrm{N}_{\mathrm{i}}$ & $\sigma_{\mathrm{i}}$ & $\mathrm{N}_{\mathrm{i}}$ & $\mathrm{n}_{\mathrm{i}} / \mathrm{N}_{\mathrm{i}}$ \\
\hline 1 & 100.00 & 21.53 & $8.43 \mathrm{E}+06$ & $1.19 \mathrm{E}-07$ & 26.30 & $4.63 \mathrm{E}+06$ & $2.16 \mathrm{E}-07$ \\
\hline 5 & 88.18 & 18.99 & $1.23 \mathrm{E}+07$ & 4.07E-07 & 23.19 & $6.75 \mathrm{E}+06$ & $7.41 \mathrm{E}-07$ \\
\hline 10 & 83.30 & 17.93 & $1.46 \mathrm{E}+07$ & $6.85 \mathrm{E}-07$ & 21.91 & $8.00 \mathrm{E}+06$ & $1.25 \mathrm{E}-06$ \\
\hline 50 & 72.46 & 15.60 & $2.22 \mathrm{E}+07$ & $2.26 \mathrm{E}-06$ & 19.06 & $1.22 \mathrm{E}+07$ & $4.11 \mathrm{E}-06$ \\
\hline 100 & 68.00 & 14.64 & $2.68 \mathrm{E}+07$ & $3.73 \mathrm{E}-06$ & 17.88 & $1.47 \mathrm{E}+07$ & $6.80 \mathrm{E}-06$ \\
\hline 500 & 58.14 & 12.52 & $4.29 \mathrm{E}+07$ & $1.17 \mathrm{E}-05$ & 15.29 & $2.35 \mathrm{E}+07$ & $2.12 \mathrm{E}-05$ \\
\hline $10^{3}$ & 54.10 & 11.65 & $5.33 \mathrm{E}+07$ & $1.88 \mathrm{E}-05$ & 14.23 & $2.92 \mathrm{E}+07$ & $3.42 \mathrm{E}-05$ \\
\hline $5 * 10^{3}$ & 45.22 & 9.73 & $9.12 \mathrm{E}+07$ & $5.48 \mathrm{E}-05$ & 11.89 & $5.00 \mathrm{E}+07$ & $9.99 \mathrm{E}-05$ \\
\hline $10^{4}$ & 41.60 & 8.96 & $1.17 \mathrm{E}+08$ & $8.54 \mathrm{E}-05$ & 10.94 & $6.43 \mathrm{E}+07$ & $1.56 \mathrm{E}-04$ \\
\hline $5 * 10^{4}$ & 33.69 & 7.25 & $2.20 \mathrm{E}+08$ & $2.27 \mathrm{E}-04$ & 8.86 & $1.21 \mathrm{E}+08$ & $4.13 \mathrm{E}-04$ \\
\hline $10^{5}$ & 30.50 & 6.57 & $2.97 \mathrm{E}+08$ & $3.36 \mathrm{E}-04$ & 8.02 & $1.63 \mathrm{E}+08$ & $6.13 \mathrm{E}-04$ \\
\hline $5^{*} 10^{5}$ & 23.57 & 5.08 & $6.44 \mathrm{E}+08$ & 7.77E-04 & 6.20 & $3.53 \mathrm{E}+08$ & $1.42 \mathrm{E}-03$ \\
\hline $10^{6}$ & 20.80 & 4.48 & $9.37 \mathrm{E}+08$ & $1.07 \mathrm{E}-03$ & 5.47 & $5.14 \mathrm{E}+08$ & $1.95 \mathrm{E}-03$ \\
\hline $5 * 10^{6}$ & 14.85 & 3.20 & $2.57 \mathrm{E}+09$ & $1.94 \mathrm{E}-03$ & 3.91 & $1.41 \mathrm{E}+09$ & $3.54 \mathrm{E}-03$ \\
\hline $10^{7}$ & 12.50 & 2.69 & $7.21 \mathrm{E}+11$ & $1.39 \mathrm{E}-05$ & 3.29 & $2.65 \mathrm{E}+11$ & $3.77 \mathrm{E}-05$ \\
\hline $5 * 10^{7}$ & 7.53 & 1.62 & $9.09 \mathrm{E}+12$ & $5.50 \mathrm{E}-06$ & 1.98 & $3.34 \mathrm{E}+12$ & $1.50 \mathrm{E}-05$ \\
\hline \multirow[t]{2}{*}{$10^{8}$} & 5.60 & 1.21 & $4.00 \mathrm{E}+13$ & $2.50 \mathrm{E}-06$ & 1.47 & $1.47 \mathrm{E}+13$ & $6.81 \mathrm{E}-06$ \\
\hline & & & $\mathrm{D}_{\mathrm{d}}=$ & 0.0045 & & $\mathrm{D}_{\mathrm{d}}=$ & 0.0083 \\
\hline
\end{tabular}

a. $\mathrm{n}_{\mathrm{i}}$ is the theoretical number of cycles associated with the stress level, $\Delta \mathrm{S} / \mathrm{S}_{\mathrm{k}}$ load and stress percentage of the effect due to wind with 50 years return period, $\sigma_{\mathrm{i}}$ is the stress at the structural detail under consideration, $\mathrm{N}_{\mathrm{i}}$ is the number of cycles leading to fatigue failure

Again the fatigue check is fulfilled with this methodology and an overestimation of the fatigue life of the towers is observed. In this methodology a great sensitivity regarding the shell thickness is observed since the reduction in shell thicknesses between the towers is about $20 \%$, while their fatigue life differs about $70 \%$ regarding the WELD detail and 55\% regarding FLANGE detail.

\section{Conclusion}

The present study evaluates the effect of shell thickness reduction on the fatigue life calculation of steel tubular wind turbine towers. The evaluation is conducted following two different procedures, one with detailed time-history loading and one with stress evaluation through analytical equation. The analysis 
methodology a which uses more detailed loading histories, assesses the welded connections in a more accurate way compared to conventional static loading analyses that are widely used and require simplification assumptions. The detailed analysis shows lower values of fatigue life for both towers compared to the more conservative and conventional Method B that calculates stress ranges based on Eurocode analytical equations. In both analyses methods and for both structural details, Tower-1 with thicker shell thicknesses appears to have a longer fatigue life compared to Tower-2 indicating that shell thickness is an important factor in the determination of the tower behavior against fatigue loading. The two towers differ in terms of total material used of about $20 \%$. In both methods a satisfactory fatigue life of the towers is calculated, indicating that even with more detailed and demanding analyses, thinner shell thicknesses serve for economical structure construction along with satisfactory fatigue life. The conventional fatigue life calculation with Method B shows that with a reduction of $20 \%$ in steel mass the fatigue life of the structure falls about $55-70 \%$. This is an explanatory remark for cases of structures subjected to cyclic loading with over $10^{8}$ cycles, that are constructed with increased tower shell thicknesses in order to limit the stress range variation under the cut-off limit. With the present study, using time-history loading, the fatigue life of the structure falls about $50-65 \%$ with the same reduction in shell thicknesses. This proves that an increase in tower shell thicknesses is often leading to the construction of non-economical structures with unnecessarily increased fatigue life.

\section{Acknowledgement}

The first author wants to express her gratitude to IKY for financial support of the research activities on performing her PhD thesis through the IKY Fellowship of Excellence for Postgraduate Studies in Greece SIEMENS Program.

This research has been co-financed by the European Union (European Social Fund-ESF) and Greek national funds through the Operational Program "Education and Lifelong Learning" of the National Strategic Reference Framework (NSRF) Research Funding Program: THALES: Reinforcement of the interdisciplinary and/or inter-institutional research and innovation.

\section{Author's Contributions}

All the authors of this manuscript contributed equally to the preparation, development and publication of the scientific work.

\section{Ethics}

The authors confirm that this article is original and contains previously unpublished material. The corresponding author verifies that other authors have read and approved the manuscript and no ethical issues are violated.

\section{References}

Bazeos, N., G.D. Hatzigeorgiou, I.D. Hondros, H. Karamaneas and D.L. Karabalis et al., 2002. Static, seismic and stability analyses of a prototype wind turbine steel tower. Eng. Structures, 24: 1015-1025. DOI: 10.1016/S0141-0296(02)00021-4

Bild, 2014. Windrad-Riese einfach umgefallen. Bild.

Bzdawka, K., 2011. Structural analysis of a wind turbine tower-steel tubular towers of heights: $76.15 \mathrm{~m}$ and 105.0m. MSc Thesis, Poznan University of Technology, Poznan, Poland.

Chou, J.S. and W.T. Tu, 2011. Failure analysis and risk management of a collapsed large wind turbine tower. Eng. Failure Analysis, 18: 295-313. DOI: $10.1016 /$ j.engfailanal.2010.09.008

Cicero, S., R. Lacalle, K. and R. Cicero, 2009. Estimation of the maximum allowable lack of penetration defects in circumferential butt welds of structural tubular towers. Eng. Structures, 31: 2123-2131. DOI: 10.1016/j.engstruct.2009.03.013

DS, 2012. Abaqus analysis user's manual. Dassault Systemes, Abaqus 6.12, Providence, RI, USA.

Dimopoulos, C. and C. Gantes. 2012. Experimental investigation of buckling of wind turbine tower cylindrical shells with opening and stiffening under bending. Thin-Walled Structures, 54: 140-155. DOI: 10.1016/j.tws.2012.02.011

Nussbaumer, A., L. Borges and L. Davaine, 2011. Fatigue Design of Steel and Composite Structures. 1st Edn., Wiley, Berlin, ISBN-10: 3433029814, pp: 334.

EC, 2003. Eurocode 3: Design of steel structures-Part 1-9: Fatigue. CEN, Brussels, Belgium.

EC, 2005a. Eurocode 3: Design of steel structures-Part 1-8: Design of Joints. CEN, Brussels, Belgium.

EC, 2005b. Eurocode 1: Actions on structures-Part 1-4: General actions-Wind actions. CEN, Brussels, Belgium.

IEC, 2005. Wind Turbines-Part 1: Design Requirements. IEC, Geneva, Switcherland.

Jiang, W., Q. Fan and J. Gong, 2010. Optimization of welding joint between tower and bottom flange based on residual stress considerations in a wind turbine. Energy, 35: 461-467. DOI: $10.1016 /$ j.energy.2009.10.012

Jonkman, J., 2005. FAST. Department of Energy, NWTC Information Portal, U.S. 
Kelley, N. and B. Jonkman, 2012. TurbSim. Department of Energy, NWTC Information Portal, U.S.

Khatri, D., 2009. Structural Failures of Wind Towers and Dynamic Analysis Procedures. URS Corporation, Los Angeles, CA.

Lacalle, R., S. Cicero, J.A. Alvarez, R. Cicero and V. Madrazo, 2011. On the analysis of the causes of cracking in a wind tower. Eng. Failure Analysis, 18: 1698-1710. DOI: 10.1016/j.engfailanal.2011.02.012

Laino, D.J., 2013. AeroDyn. Department of Energy, NWTC Information Portal, U.S.

Lavassas, I., G. Nikolaidis, P. Zervas, E. Efthymiou and I.N. Doudoumis et al., 2003. Analysis and design of the prototype of a steel 1-MW wind turbine tower. Eng. Structures, 25: 1097-1106. DOI: 10.1016/S0141-0296(03)00059-2

Lee, K.S. and H. Bang, 2013. A study on the prediction of lateral buckling load for wind turbine tower structures. Int. J. Precision Eng. Manufacture, 13: 1829-1836. DOI: $10.1007 / \mathrm{s} 12541-012-0240-y$

Lotsberg, I., 2009. Stress concentrations due to misalignment at butt welds in plated structures and at girth welds in tubular. Int. J. Fatigue, 31: 1337-1345. DOI: 10.1016/j.ijfatigue.2009.03.005

NREL, 2015. National Renewable Energy Laboratory. Department of Energy, U.S.
NWTC, 2015. National Wind Technology Center. Department of Energy, U.S.

Raftery, M., 2012. The dark side of "green": Wind turbine accidents, injuries and fatalities raise serious safety concerns. East County Magazine.

Ragheb, M., 2013. Safety of wind systems. Wind Power Systems Course material, University of Illinois at Urbana-Champaign, USA.

Stathopoulos, T. and C.C. Baniotopoulos, 2007. Wind Effects on Buildings and Design of Wind-Sensitive Structures. 1st Edn., Springer Science and Business Media, New York, ISBN-10 3211730761, pp: 238.

Thanasoulas, I., K.G. Koulatsou and C.J. Gantes, 2014. Nonlinear numerical simulation of the response of bolted ring flanges in wind turbine towers. Proceedings of the 8th Hellenic National Conference of Steel Structures, Oct. 2-4, Metal Structures Research Society, Greece, pp: 159-159.

Veljkovic, M., C. Heistermann and W. Husson, 2006. High-strength tower in steel for wind turbines. Published Technical Report, Publications Office of the European Union, Brussels, Belgium.

Veljkovic, M., M. Feldmann, J. Naumes, D. Pak and C. Rebelo et al., 2010. Friction connection in tubular towers for a wind turbine. Stahlbau, 79: 660-668. DOI: $10.1002 /$ stab. 201001365 